\title{
Supratentorial and infratentorial brain abscess
}

\author{
Miguel Gelabert-González • Ramón Serramito-García • \\ Eduardo Aran-Echabe
}

Received: 13 March 2012 /Accepted: 15 March 2012 /Published online: 1 April 2012

(C) Springer-Verlag 2012

\section{Dear Editor,}

We would like to make the following observations, on the basis of our personal experience, in relation to the recent article by Landriel et al. [3] on supratentorial and infratentorial brain abscesses.

First, the authors include a toxoplasmosis case within the group of abscesses studied. Toxoplasmosis is a disease caused by an obligate intracellular protozoal parasite, Toxoplasma gondii; it is the most common cause of focal brain lesions in patients with AIDS. In this cases, the clinical, radiological and pathological characteristics are different from those of bacterial infection, and for this reason they are not usually included in the literature on brain abscesses [4].

Secondly, the authors report only six paediatric cases. In our experience and in the literature review, paediatric cases represent $15-25 \%$ of all cases treated. Perhaps the authors could indicate if the low percentage is due to circumstances specific to their hospital catchment area $[1,2]$.

We are struck by the fact that the authors use so many different approaches in the treatment of brain abscess (up to 15 different antibiotic treatment protocols). Our own local protocol for initial empirical antimicrobial therapy includes a combination of vancomycin, third-generation cephalosporin and metronidazole. Between 3 and 5 days later, we either continue with the same treatment or modify it according to the literature and the results of sensitivity tests [1].
Finally, we are surprised by the low percentage of negative cultures obtained. In most of the literature, and in our own experience, negative results represent $15-30 \%$ of all cultures $[1,2,4]$. Perhaps the authors could indicate what accounts for this low percentage.

Conflicts of interest None.

\section{References}

1. Gelabert-González M, Serramito-García R, García-Allut A, CutrínPrieto J (2008) Management of brain abscess in children. J Pediatr Child Health 44:731-735

2. González-García J, Gelabert M, Pravos AG, Villa JMF (1999) Intracranial collections of pus. A review of 100 cases. Rev Neurol 29:416-424

3. Landriel F, Ajler P, Hem S, Bendersky D, Goldschmidt E, Garategui L, Vecchi E, Konsol O, Karrizo A (2012) Supratentorial and infratentorial brain abscesses: surgical treatment, complications and outcomes - a 10-year single-center study. Acta Neurochir (Wien). doi:10-1007/s00701-012-1299-z

4. Nathoo N, Nadvi SS, Narotam PK, van Dellen JR (2011) Brain abscess: management and outcome analysis of a computed tomography era experience with 973 patients. World Neurosurg 75:716726

M. Gelabert-González $(\bowtie) \cdot$ R. Serramito-García $•$

E. Aran-Echabe

Department of Surgery, University of Santiago de Compostela,

Clinic Hospital of Santiago de Compostela, A Choupana,

15706 Santiago de Compostela, Spain

e-mail: miguel.gelabert@usc.es 